\title{
2D X-ray and FTIR micro-analysis of the degradation of cadmium yellow pigment in paintings of Henri Matisse
}

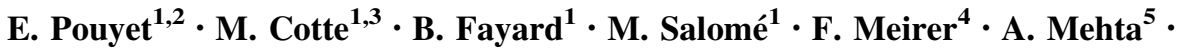 \\ E. S. Uffelman ${ }^{6}$ A. Hull ${ }^{7}$ F. Vanmeert ${ }^{8} \cdot$ J. Kieffer $^{1} \cdot$ M. Burghammer ${ }^{1}$ \\ K. Janssens ${ }^{8} \cdot$ F. Sette ${ }^{1} \cdot$ J. Mass ${ }^{9}$
}

Received: 20 March 2015 / Accepted: 13 May 2015/Published online: 3 June 2015

(C) Springer-Verlag Berlin Heidelberg 2015

\begin{abstract}
The chemical and physical alterations of cadmium yellow (CdS) paints in Henri Matisse's The Joy of Life (1905-1906, The Barnes Foundation) have been recognized since 2006 , when a survey by portable X-ray fluorescence identified this pigment in all altered regions of the monumental painting. This alteration is visible as fading, discoloration, chalking, flaking, and spalling of several regions of light to medium yellow paint. Since that time, synchrotron radiation-based techniques including elemental and spectroscopic imaging, as well as X-ray scattering have been employed to locate and identify the alteration products observed in this and related works by Henri Matisse. This information is necessary to formulate one or multiple mechanisms for degradation of Matisse's paints from this period, and thus ensure proper environmental conditions for the storage and the display of his works. This paper focuses on 2D full-field X-ray Near Edge Structure imaging, 2D micro-X-ray Diffraction, X-ray Fluorescence,
\end{abstract}

Electronic supplementary material The online version of this article (doi:10.1007/s00339-015-9239-4) contains supplementary material, which is available to authorized users.

E. Pouyet

emelinepouyet@gmail.com

1 European Synchrotron Radiation Facility, 6, rue Jules Horowitz, 38000 Grenoble, France

2 ARC-Nucléart - CEA/Grenoble, 17 rue des Martyrs, 38054 Grenoble Cedex 9, France

3 LAMS (Laboratoire d'Archéologie Moléculaire et Structurale) UMR-8220, 3 rue Galilée, 94200 Ivry-sur-Seine, France

4 Inorganic Chemistry and Catalysis, Debye Institute for Nanomaterials Science, Utrecht University, Universiteitsweg 99, 3584 CG Utrecht, The Netherlands and Fourier Transform Infra-red imaging of the altered paint layers to address one of the long-standing questions about cadmium yellow alteration-the roles of cadmium carbonates and cadmium sulphates found in the altered paint layers. These compounds have often been assumed to be photo-oxidation products, but could also be residual starting reagents from an indirect wet process synthesis of CdS. The data presented here allow identifying and mapping the location of cadmium carbonates, cadmium chlorides, cadmium oxalates, cadmium sulphates, and cadmium sulphides in thin sections of altered cadmium yellow paints from The Joy of Life and Matisse's Flower Piece (1906, The Barnes Foundation). Distribution of various cadmium compounds confirms that cadmium carbonates and sulphates are photo-degradation products in The Joy of Life, whereas in Flower Piece, cadmium carbonates appear to have been a [(partially) unreacted] starting reagent for the yellow paint, a role previously suggested in other altered yellow paints.

5 Stanford Synchrotron radiation Lightsource, SLAC National Accelerator Laboratory, 2575 Sand Hill Rd., Menlo Park, CA, USA

6 Department of Chemistry and Biochemistry, Washington and Lee University, Lexington, VA 24450, USA

7 Department of Chemistry and Biochemistry, University of Delaware, Newark, DE, USA

8 AXES Research Group, Department of Chemistry, University of Antwerp, Groenenborgerlaan 171, 2020 Antwerp, Belgium

9 Scientific Research and Analysis Laboratory, Conservation Department, Winterthur Museum, Winterthur, DE 19735, USA 


\section{Introduction}

With the rapid rise of chemical industry during the end of the nineteenth century and the beginning of the twentieth century, numerous new inorganic and organic pigments were developed and introduced as alternatives to wellestablished traditional pigments, often outclassing them thanks to their colour intensity, purity, cost, and covering power. However, in Impressionist and early Modernist paintings, various synthetic inorganic pigments have started to undergo chemical and physical degradation phenomena ranging from fading and colour shifts to spalling and flaking. Several examples of the discoloration of synthetic yellow pigments from the turn of the twentieth century (e.g. zinc yellow $\left(\mathrm{K}_{2} \mathrm{O} \cdot 4 \mathrm{ZnCrO}_{4} \cdot 3 \mathrm{H}_{2} \mathrm{O}\right)$ [1], chrome yellow $\left(\mathrm{PbCrO}_{4}\right)$ [2-6], and cadmium yellow (CdS) $[7,8]$ ) have been recently reported.

In particular, despite having a good reputation regarding permanency, physical manifestations of photo-oxidative degradation of yellow cadmium sulphide (CdS) pigments have been observed over the past decade in works by Pablo Picasso, Vincent Van Gogh, Georges Seurat, Henri Matisse, Ferdinand Leger, Edvard Munch, and James Ensor [7-10]. This degradation appears in many different ways; from paint chalking, i.e. drying and crumbling, to fading, flaking, spalling, and in its most advanced cases to the formation of a thick $(20-50 \mu \mathrm{m})$ ivory to tan alteration crusts covering the original yellow paint.

The first systematic study of CdS pigment degradation was performed in 2005 by Leone et al. [9] on 12 paintings dating from 1887-1923. In this study, based on X-ray diffraction (XRD) and scanning electron microscopy combined with an energy-dispersive spectrometry (SEM-EDS), the presence of different oxidized $\mathrm{Cd}$ species, including cadmium carbonate $\left(\mathrm{CdCO}_{3}\right)$, cadmium hydroxide $\left(\mathrm{Cd}(\mathrm{OH})_{2}\right)$, and cadmium sulphate $\left(\mathrm{CdSO}_{4}\right)$ was observed at the surface of paintings; these materials were identified as the main products of the degradation process. Combining these observations with the results from artificially degraded mock-ups and supplementary time-of-flight-secondary ion mass spectrometry (ToF-SIMS) analyses of the surface of the painting samples, a preliminary degradation mechanism was suggested. The photo-oxidation of the $\mathrm{CdS}$ pigment was proposed to generate $\mathrm{CdO}, \mathrm{CdSO}_{4}$, and $\mathrm{SO}_{2}$ gas, which in high relative humidity environments, convert to $\mathrm{H}_{2} \mathrm{SO}_{4}$ resulting in acid hydrolysis of the paint binding medium.

In 2009 and 2012, Van der Snickt et al. [7, 8] extended the study of CdS pigment degradation to paintings by James Ensor and Vincent van Gogh by using synchrotron radiation (SR)-based techniques. In the case of Still Life with Cabbage by James Ensor [7], the degradation of yellow CdS was related to the photo-oxidation of the cadmium sulphide to (hydrated) cadmium sulphate $\left(\mathrm{CdSO}_{4} \cdot \mathrm{nH}_{2} \mathrm{O}\right)$. Repeated hydration and drying of the paint surface resulted in the formation of a thin (a few microns thick) layer of semi-transparent whitish globules of $\mathrm{CdSO}_{4} \cdot \mathrm{nH}_{2} \mathrm{O}$ on the surface of the CdS-based paint. Another notable finding of this study was the identification of $\left(\mathrm{NH}_{4}\right)_{2} \cdot \mathrm{Cd}_{2}\left(\mathrm{SO}_{4}\right)_{3}$ in the pigment layer, thought to be related to a previous aggressive cleaning treatment with dilute ammonia. Two supplementary degradation products were identified in the case of the Flowers in a blue vase by Vincent Van Gogh [8]: cadmium oxalate $\left(\mathrm{CdC}_{2} \mathrm{O}_{4}\right)$ and lead sulphate $\left(\mathrm{PbSO}_{4}\right)$. The presence of an apparently unoriginal varnish, likely applied after the initial deterioration of the CdS yellow, was the possible source of $\mathrm{C}_{2} \mathrm{O}_{4}{ }^{2-}$ and $\mathrm{Pb}^{2+}$ ions. These ions could have then reacted with $\mathrm{Cd}^{2+}$ and $\mathrm{SO}_{4}^{2-}$ ions, produced during the initial photooxidation of $\mathrm{CdS}$, leading to the formation of a thin layer of $\mathrm{CdC}_{2} \mathrm{O}_{4}$ on the top of the painting surface and the precipitation of $\mathrm{PbSO}_{4}$ in the varnish layer.

Simultaneously, Mass et al. [11], from the Conservation Department of the Winterthur Museum, initiated a study to characterize visible changes observed in cadmium yellow areas of The Barnes Foundation's The Joy of Life (Henri Matisse, 1905-1906, Barnes Foundation 719, Fig. 1a), in particular for preservation purposes. Studies were performed at different synchrotron facilities: at ID21 (ESRF), at BL4-3 (SSRL) [11], and at the IRENI (Synchrotron Radiation Center, SRC) [12, 13]. By combining microFourier transform infrared ( $\mu$ FTIR) spectroscopy with micro-X-ray fluorescence ( $\mu \mathrm{XRF}$ ) and micro-X-ray near edge structure ( $\mu$ XANES) spectroscopy (at the $\mathrm{Cd} \mathrm{L}_{\mathrm{III}}$-edge and at the S K-edge in scanning mode), spectra were collected over dozens of points. Degradation products were identified in the altered cadmium yellow area from the darkened yellow foliage at the upper left of the painting (three samples: S111, S112, and S113 in Fig. 1b), the yellow fruit in the tree with an ivory-coloured alteration crust at the upper right, (one sample: S115 in Fig. 1b), and in the faded yellow field beneath the central reclining figures (two samples: S117 and S5 in Fig. 1 b). $\mathrm{CdCO}_{3}$ was present in high concentrations in all altered regions, supporting the hypothesis that it is more likely a poorly soluble photodegradation product than a filler or residual starting reagent. In the unaltered yellow paint, the identification of $\mathrm{CdS}$ and $\mathrm{CdCl}_{2} \cdot \mathrm{nH}_{2} \mathrm{O}$ suggested that chloride was introduced as the starting reagent for the synthesis of the cadmium yellow. $\mathrm{CdSO}_{4} \cdot \mathrm{nH}_{2} \mathrm{O}$ was also found to be enriched in the off-white alteration layers of the samples studied; as a more soluble species, it was also found elsewhere in the cross sections. Alteration crusts identified had no remaining CdS, all of which had degraded into a mixture of cadmium sulphates, carbonates, and oxalates. 
Fig. 1 a Henri Matisse, French, 1869-1954 The Joy of Life, between October 1905 and March 1906, oil on canvas, $691 / 2 \times 94 \frac{3}{4}$ in.

$(176.5 \times 240.7 \mathrm{~cm})$, oil on canvas, The Barnes Foundation, BF719; c upper left zoom showing tan-brown alteration crusts on the yellow foliage and on the yellow fruit in the tree at the upper right, and zoom on the faded region below the central reclining figures, sampling locations for this study are represented by black cross; b Henri Matisse, French, 1869-1954 Flower Piece, 1906, $217 / 8 \times 18 \frac{1}{4}$ in.

$(55.6 \times 46.4 \mathrm{~cm})$, oil on canvas, The Barnes Foundation, BF205; d altered (brown) and non-altered (yellow) regions of yellow paint to the right of the pitcher, sampling locations are represented by black cross
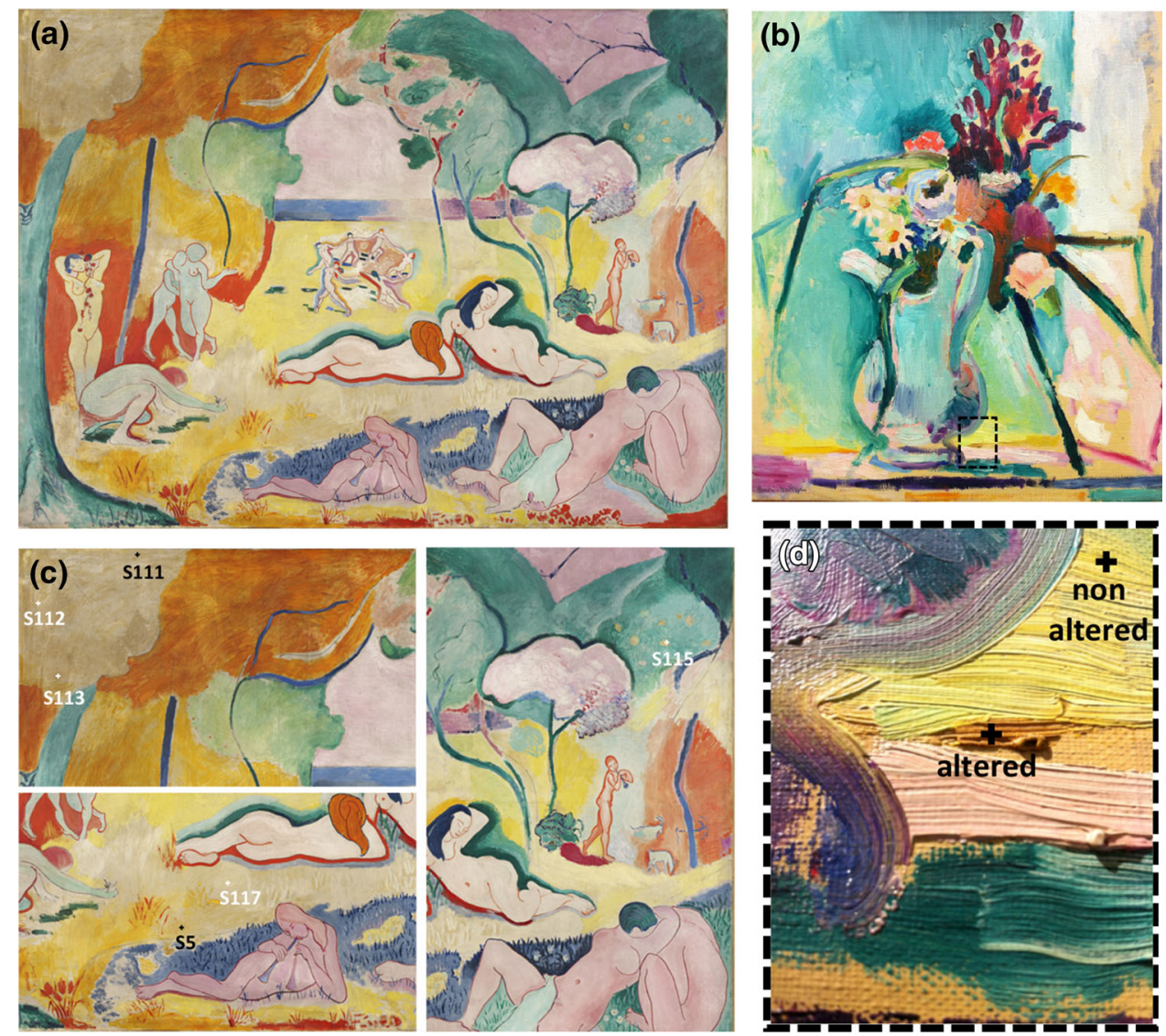

These examples illustrate several advantages of combining synchrotron radiation-based X-ray techniques, such as $\mu \mathrm{XRF}, \mu \mathrm{XANES}$, and $\mu \mathrm{XRD}$ to elucidate the degradation processes of paint containing $\mathrm{CdS}$ yellow pigment. First, combined techniques allow the identification of minor and major components even when present as amorphous/nanocrystalline materials (as in the case of CdS) or in a crystallized form. The sensitivity of these SR-techniques is critical for the identification of photo-alteration products in paintings, allowing for preventive conservation measures (such as closer management of light levels and relative humidity) to be implemented when degradation is observed.

Secondly, the micrometric resolution of these probes is essential to reveal the presence of the degradation/alteration layer on the painting's surface, which is typically only a few microns thick, and to establish the stratigraphy of the alteration/degradation products. The identification of $\mathrm{CdCO}_{3}$ and $\mathrm{CdSO}_{4-}$ $\mathrm{nH}_{2} \mathrm{O}$ alone does not constitute a conclusive proof for a photo-oxidation process. Both compounds are known to be reagents in the wet and/or dry synthesis process of CdS. Thus, their identification as either unreacted starting reagents, side products of the original synthesis, or as degradation compounds relies mostly on their location and distribution in regards to the original paint layer.

Mass et al. [11] demonstrated the interest of using a scanning probe to accurately localize and identify the stratigraphy of various species in order to decide whether a particular species can be categorized as unreacted starting reagents or as degradation compounds. However, the recent use of 2D full-field XANES (FF-XANES), combined with $2 \mathrm{D} \mu \mathrm{FTIR}, \mu \mathrm{XRF}$ and $\mu \mathrm{XRD}$ measurements when speciation through XANES is ambiguous, has allowed faster and more detailed identification and distribution of various chemical compounds, even in highly complex and heterogeneous sections. The new approach allows for a deeper elucidation of the degradation phenomena under way, leading to more specific preservation recommendations, and the ability to identify degradation at an earlier stage. In particular, the full-field analysis appears to be an ideal way to extend this study over an entire $2 \mathrm{D}$ region and to eliminate some of the ambiguities that are inherently present when only a point-by-point analysis is performed. 


\section{Experimental}

\subsection{Paintings and samples location}

In order to complete the identification and localization of the original paint components and the degradation materials, two micrometric fragments S111 and S5 were sampled from The Joy of Life painting (Fig. 1a), in the altered cadmium yellow paint from the darkened yellow foliage at the upper left of the work, and in the faded yellow field beneath the central reclining figures, respectively (Fig. 1b).

Two other fragments (named BF205-darkened and BF205-undarkened) were sampled from the Flower Piece painting (Fig. 1c), from the dry and cracked darkened region below the right side of the pitcher, and the intact yellow region above this darkened area (Fig. 1d), respectively. This sampling strategy was devised to compare degradation phenomena in two of Matisse's artworks showing two different stages of photo-degradation and to obtain information on the cadmium yellow pigment synthesis in the paints used by Matisse.

\subsection{Sample preparation and mounting}

In previous work [11], X-ray analyses were carried out on the surfaces of polished cross sections of painting fragments embedded in polyester resin, the most classical approach to prepare transversal sections from paint fragments. One unpublished result obtained following this sample preparation method is detailed below for sample S5. The examination of samples from historical paintings using combined elemental, molecular, and structural methods benefits from the preparation of thin sections [14]. Ideally, hyperspectral analyses are performed on a unique section. However, the sample preparation requirements (thickness, embedding media, etc.) differ as a function of the techniques involved [15]. Accordingly, in the present study, two adapted thin sections were prepared: one for combined XANES and XRD analyses, and another one for FTIR analyses. For X-ray-based techniques, the sample was first embedded using synthetic resin (Historesin, Leica) and microtomed to obtain a section thinner than $20 \mu \mathrm{m}$. The section was then sandwiched between two ultralene foils ( $4 \mu \mathrm{m}$ thick, from Spex Sample Prep) to provide mechanical stability during data acquisition. For $\mu$ FTIR analysis, micro-compression was favoured because it prevents spectral contamination from the embedding material [12, 13]. Considering that $\mu \mathrm{XRF}$ results are not affected by any of these forms of sample preparation (compressed sample between diamond windows, cross section, and thin section from embedded fragment), the resulting elemental maps allow the combination of results from X-ray and infrared spectroscopies together with the visible observations.

\subsection{Analytical methods and data processing}

\subsubsection{Micro-X-ray fluorescence and chemical maps in scanning mode}

$\mu \mathrm{XRF}$ data were collected at the X-ray micro-spectroscopy beamline ID21 at the European Synchrotron Radiation Facility (ESRF) [16]. Monochromatic radiation was extracted from an undulator coupled with a fixed-exit doublecrystal monochromator equipped with a $\mathrm{Si}(111)$ crystal and focused using a Kirkpatrick-Baez mirror pair to a typical beam size of $0.2 \mu \mathrm{m}$ ver. $\times 0.6 \mu \mathrm{m}$ hor. with a flux ranging from $10^{9}$ to $10^{10} \mathrm{ph} / \mathrm{s}$ and an energy ranging from 2 to $9 \mathrm{keV}$. The samples were mounted in a vertical plane, at an angle of $60^{\circ}$ with respect to the beam, and raster scanned in the beam using a combination of stepper motors and piezo actuators. The XRF data were collected by a single channel solid state detector. This allowed the distribution of the different elements present in the paint cross sections, in particular of the Cd- and S-containing compounds, to be mapped at sub-micrometre resolution. In a few cases, the elemental composition maps were complemented by sulphur speciation maps. Two maps were recorded setting the energy of the incoming X-rays to 2.4728 and $2.4825 \mathrm{keV}$, respectively, i.e. to energies where the absorption and consecutively the XRF from sulphides $\left(\mathrm{S}^{2-}\right)$ or sulphates $\left(\mathrm{S}^{6+}\right)$ is enhanced. By assuming a binary composition consisting of $\mathrm{CdS}$ and $\mathrm{CdSO}_{4} \cdot \mathrm{nH}_{2} \mathrm{O}$ and determining the absorption of these two compounds at these two specific energies, it is possible to derive the concentration maps of $\mathrm{CdS}$ and $\mathrm{CdSO}_{4} \cdot \mathrm{nH}_{2} \mathrm{O}$, as detailed elsewhere [7, 17]. The XRF data were batch fitted using the PyMca software package [18].

\subsubsection{Full-field XANES}

In FF-XANES measurements, a stack of X-ray radiographs of a thin sample is acquired, while tuning the X-ray energy across the absorption edge of the element of interest [19]. This novel technique allows the acquisitions of millions of XANES spectra in a very short time (less than $1 \mathrm{~h}$ per acquisition) and makes possible the acquisition of full XANES spectra at the micrometre scale over millimetric $2 \mathrm{D}$ regions.

FF-XANES data were collected at ID21 in the full-field configuration, across the $\mathrm{S}$ K-edge, $\mathrm{Cl} \mathrm{K}$-edge, and $\mathrm{Cd} \mathrm{L}_{\mathrm{III}^{-}}$ edge. The beam size of $1.5 \times 1.5 \mathrm{~mm}^{2}$ was defined using slits; the spatial structures of the beam were smoothed using an X-ray decoheror (rotating graphite foil, $125 \mu \mathrm{m}$ 
thick). Samples were mounted vertically, perpendicular to the beam, and radiographs were acquired with a detection ensemble comprising a scintillator, a magnifying objective, and a CCD camera. It resulted in images with a pixel size of $300 \times 300 \mathrm{~nm}^{2}$ and a field of view of $315 \times 360 \mu \mathrm{m}^{2}$.

For data analysis, the $10^{6}$ XANES spectra acquired in full-field mode were fitted as a linear combination (LC) of references, using the TXM-Wizard software [20]. The primary set of $\mathrm{Cd}$ reference compounds (spectra presented in Fig. 2) was composed of: cadmium sulphate $\left(\mathrm{CdSO}_{4}\right.$, $99.99 \%$ metals basis), hydrated cadmium sulphate $\left(\mathrm{CdSO}_{4} \cdot \mathrm{nH}_{2} \mathrm{O}, 99.999 \%\right.$ metals basis$)$, cadmium sulphide (CdS, $99.995 \%$ metals basis), cadmium nitrate tetrahydrate $\left(\mathrm{Cd}\left(\mathrm{NO}_{3}\right)_{2} \cdot 4 \mathrm{H}_{2} \mathrm{O},>99.999 \%\right.$ metals basis $)$, cadmium oxide (CdO, $>99.99 \%$ metals basis), hydrated cadmium chloride $\left(\mathrm{CdCl}_{2} \cdot \mathrm{nH}_{2} \mathrm{O},>99.99 \%\right.$ metals basis $)$, cadmium carbonate $\left(\mathrm{CdCO}_{3},>99.999 \%\right.$ metals basis) (all purchased from Sigma Aldrich) and cadmium oxalate (synthesized at Washington and Lee University). The final choice of references for the least squares fitting (LSLC) varies from one sample to another, with regards to complementary $\mu \mathrm{XRD}$ and $\mu \mathrm{FTIR}$ results. In the case of FFXANES measurements across the $\mathrm{S}$ K-edge, the low energy of incoming photons led to a strong absorption by the sample. Even the thinnest section obtained by microtome was insufficiently thin to prevent over-absorption effects, drastically reducing the white line intensity of sulphur species, distorting spectral features, and making LSLC analysis untenable. For these data sets, the selection of Region of Interest (ROI) characteristics of the different sulphur species present was preferred as a qualitative approach.

At the $\mathrm{Cd} \mathrm{L}_{\mathrm{III}}$-edge and $\mathrm{Cl} \mathrm{K}$-edge, the transmission obtained on a $10 \mu \mathrm{m}$ section was sufficient to allow LSLC treatment. One of the most important assets of LSLC is its quantitative character, since it provides information on the relative contribution of each reference present in the mixture. However, this strategy presents an important drawback, as it necessitates an a priori knowledge of the phases constituting the sample. As for single XANES LC fitting, the method also relies on: (1) an accurate energy calibration of references and data sets; (2) a reliable choice of references (guided for example by complementary analyses by methods such as XRD, FTIR, and Raman); and (3) a reference set as close as possible to the actual composition of the sample itself to minimize differences in the background shape and in the pre- and post-edge regions between references and data sets.

These constraints and the massive data set size motivated the use of another strategy for data analyses in the case of sample S111, namely principal component

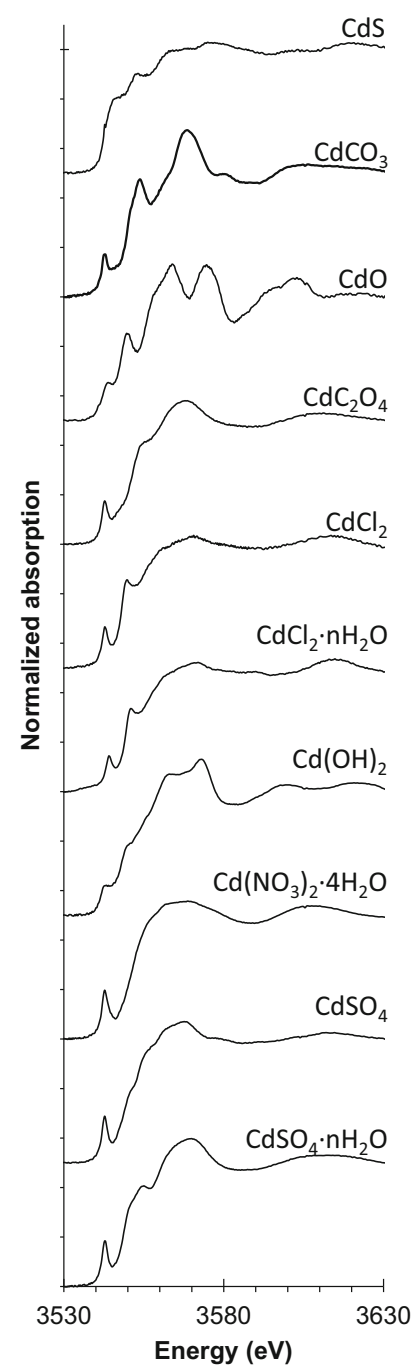

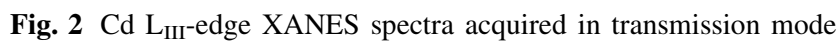
using FF-XANES technique on various cadmium references: cadmium sulphate $\left(\mathrm{CdSO}_{4}, 99.99 \%\right.$ metals basis), hydrated cadmium sulphate $\left(\mathrm{CdSO}_{4} \cdot \mathrm{nH}_{2} \mathrm{O}, 99.999 \%\right.$ metals basis $)$, cadmium sulphide (CdS, $99.995 \%$ metals basis), cadmium nitrate tetrahydrate $\left(\mathrm{Cd}\left(\mathrm{NO}_{3}\right)_{2} \cdot 4 \mathrm{H}_{2} \mathrm{O},>99.999 \%\right.$ metals basis $)$, cadmium chloride $\left(\mathrm{CdCl}_{2},>99.99 \%\right.$ metals basis$)$, hydrated cadmium chloride $\left(\mathrm{CdCl}_{2}\right.$ $\mathrm{nH}_{2} \mathrm{O},>99.99 \%$ metals basis), cadmium oxide (CdO, $>99.99 \%$ metals basis), cadmium carbonate $\left(\mathrm{CdCO}_{3},>99.999 \%\right.$ metals basis $)$ (all purchased from Sigma Aldrich), and cadmium oxalates (synthesized at Washington and Lee University)

analyses (PCA) and subsequent k-means clustering. Pixels with similar XANES spectra were pooled in reduced PC space (in the score plot), effectively segmenting the image based on the variance in the recorded XANES features into a pre-defined number of regions ( $\mathrm{k}$ areas) consisting of pixels with a similar XANES signature. PCA and clustering were performed using the TXM-Wizard software [21]. 


\subsubsection{Micro-X-ray diffraction}

Some samples (BF205 darkened and undarkened) were further studied by $\mu$ XRD at the ID13 (ESRF) and P06 (PETRA III) beamlines. At ID13, the X-ray beam energy of $12.9 \mathrm{keV}$ was selected by means of a $\mathrm{Si}(111)$ doublecrystal monochromator. The beam was focused with a Kirkpatrick-Baez mirror optic down to $2.5 \times 1.5 \mu \mathrm{m}^{2}$ (hor. $\times$ ver.). Diffraction signals were recorded in transmission geometry with a $2 \mathrm{k} \times 2 \mathrm{k}$ ESRF FReLoN detector $\left(50.0(\mathrm{~h}) \times 49.3(\mathrm{v}) \mu \mathrm{m}^{2}\right.$ pixel size $)$.

At P06, a hard-X-ray micro- and nanoprobe beamline at the PETRA III storage ring (DESY, Hamburg, Germany), the X-ray beam energy of $21 \mathrm{keV}$ was selected by means of a Si(111) double-crystal monochromator [22]. The beam was focused with a Kirkpatrick-Baez mirror optic down to $0.6 \times 0.8 \mu \mathrm{m}^{2}$ (hor. $\times$ ver.). Diffraction signals were recorded in transmission geometry with a PILATUS $300 \mathrm{~K}$ area detector.

Data were unwrapped using both XRDUA [23] and PyFAI [24]. The Match! and EVA packages were used as well during the preliminary phase identification. 2D maps of compounds were then generated with PyMca by using ROIs (each ROI corresponding to a particular diffraction angle range). These ranges were chosen based on the peak intensity and the absence of overlaps with other phases (defined in Online Resource (1)).

\subsubsection{Micro-FTIR analyses}

Organic compounds are known to play an important role in the degradation mechanisms of paint layers (e.g. through hydrolysis of the drying oil binder); moreover, some of the alteration products are organometallic compounds. Thus, complementary $\mu$ FTIR analyses in the mid-IR domain were performed at ID21. The FTIR spectromicroscope is based on a commercial instrument and is composed of a Thermo Nicolet Nexus infrared bench associated with an infrared Thermo Continuum microscope [25]. The infrared beam was emitted from a short straight section (containing focusing electron lenses) upstream of a bending magnet of the ESRF ring. The edge radiation was collected, collimated, and transferred to the spectrometer and microscope using a set of 12 mirrors. In the microscope, a $\times 32$ Schwarzschild objective was used in confocal mode; an aperture defined the size of the spot illuminating the sample. The signal was detected using a liquid $\mathrm{N}_{2}$-cooled single element $50 \mu \mathrm{m}$ MCT detector. In this configuration, the beam size was $8 \times 8 \mu \mathrm{m}^{2}$ and FTIR spectra were acquired in transmission mode using the diamond compression technique.

The OMNIC and PyMca packages were used for data analysis.

\section{Results}

\subsection{The Joy of Life (1905-1906): study of the degradation process}

\subsubsection{S5 sample: faded yellow field beneath the central reclining figures}

Following the above strategy, analyses were performed on two thin sections from the same initial S5 fragment, which had previously been analysed in scanning mode as a cross section [11].

$\mu$ FTIR was performed on a fragment prepared with the micro-compression cell (Fig. 3a). Chemical maps (recorded with a step size of $6 \times 6 \mu \mathrm{m}^{2}$ ) are presented in Fig. 3d. FF-XANES was acquired on an embedded thin section of $10 \mu \mathrm{m}$ (Fig. 3f), at the $\mathrm{Cd} \mathrm{L}_{\mathrm{III}}$-edge and the $\mathrm{Cl} \mathrm{K}$-edge (pixel size $0.6 \times 0.6 \mu \mathrm{m}^{2}$ ). $\mathrm{Cd} \mathrm{L}_{\mathrm{III}}$-spectra were fitted with the following set of references: $\mathrm{CdS}, \mathrm{CdCO}_{3}, \mathrm{CdCl}_{2} \cdot \mathrm{nH}_{2} \mathrm{O}$, and $\mathrm{CdSO}_{4} \cdot \mathrm{nH}_{2} \mathrm{O}$ based on the previous $\mu$ XANES results [11]. Results of LSLC fitting are presented in Fig. 3i. $\mu \mathrm{XRF}$ maps were acquired at $7.2 \mathrm{keV}$ (step size: $1 \times 1 \mathrm{~m}^{2}$ ) on the two sections, allowing, together with the optical observations, the correlation of results obtained with the three techniques. The elemental maps obtained on the pressed sample and the thin embedded section are shown in Fig. 3c, h, respectively. Additional speciation maps obtained in $\mu \mathrm{XRF}$ mode at the $\mathrm{S}$ K-edge from the same sample but prepared as a cross section, (pixel size: $1 \times 1 \mu^{2}$ ) are presented in Fig. 4 .

The visible images and chemical maps reveal a complex mixture and stratigraphy of Cd-based compounds in the predominately unaltered yellow region and the alteration white crust (Fig. 3b, g).

In the yellow internal region, $\mathrm{Cd}$ is highly concentrated ( $\mu$ XRF, Fig. $3 \mathrm{~h}$ ) and mainly present as CdS (confirmed by XANES at $\mathrm{Cd} \mathrm{L}_{\mathrm{III}}$-edge, Fig. $3 \mathrm{i}$ and Online Resource (2)). XANES at the $\mathrm{Cd} \mathrm{L}_{\mathrm{III}}$-edge allows the identification of other cadmium-based species as well: carbonates (confirmed by $\mu$ FTIR, Fig. $3 d$ ), sulphates (confirmed by $\mu$ FTIR, Fig. 3d, and chemical maps at S K-edge, Fig. 4), and chlorides, $\mathrm{CdCl}_{2}$ (confirmed by $\mu \mathrm{XRF}$, Fig. $3 \mathrm{c}$ and $\mathrm{h}$, and XANES at the $\mathrm{Cl}$ K-edge, Online Resource(3)). For sulphates and chlorides, improved data fitting was obtained when spectra of hydrated references were employed.

The imaging capability combined with micrometric resolution achieved with the full-field microscope reveals that $\mathrm{CdS}$ is heterogeneously present in the yellow layer and is intermixed with $\mathrm{CdCO}_{3}$ and $\mathrm{CdSO}_{4} \cdot \mathrm{nH}_{2} \mathrm{O}$ (Fig. 3i). Cadmium chlorides have been previously identified in several regions of this painting (sample S115: yellow fruit in the tree at the upper right and sample S112:darkened 
(a)

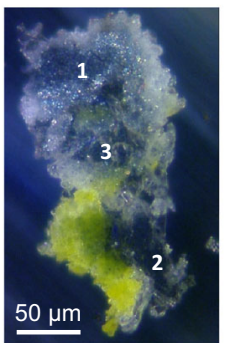

(c)

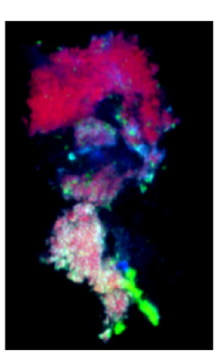

$\mathrm{s}$

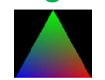

$\mathrm{Cl} \quad \mathrm{Cd}$ (b)

Oxalates Carbonates Sulfates CI, Cd

Carbonates Sulfates Cl, Cd

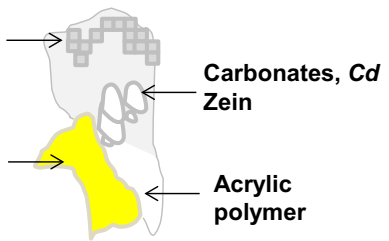

(d)

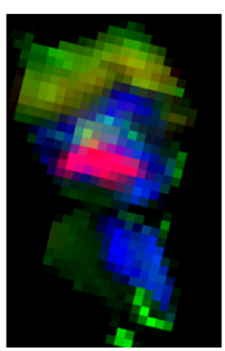

$\mathrm{O}-\mathrm{H}$

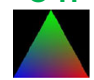

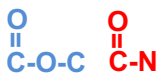
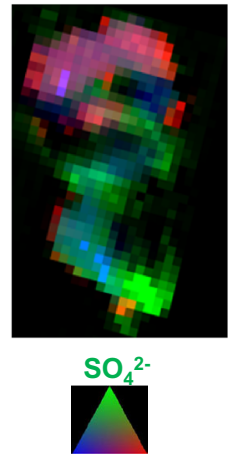

$\mathrm{CO}_{3}{ }^{2-}-\mathrm{C}_{2} \mathrm{O}_{4}$ (f)

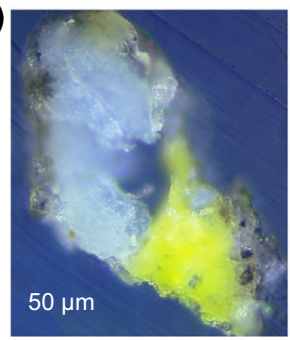

(h)
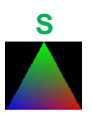

Cl Cd (g)
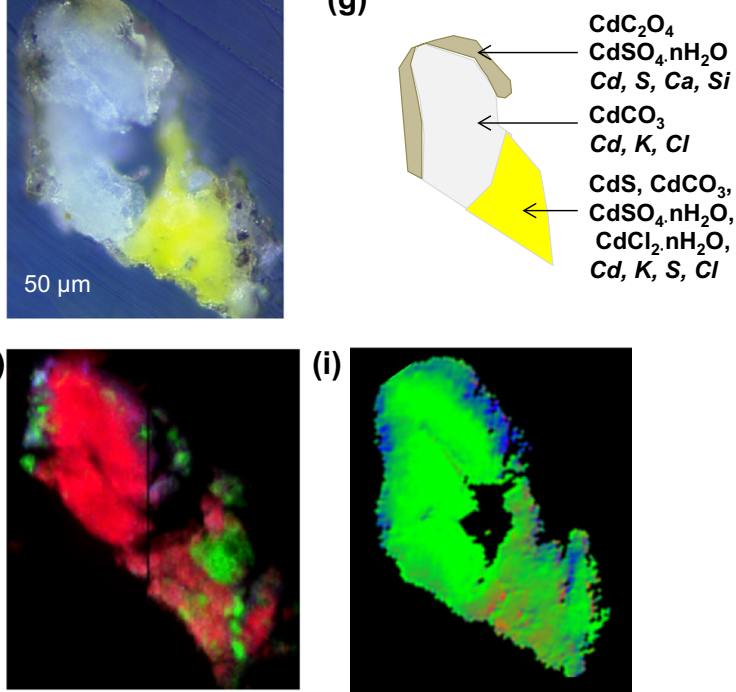

(i)

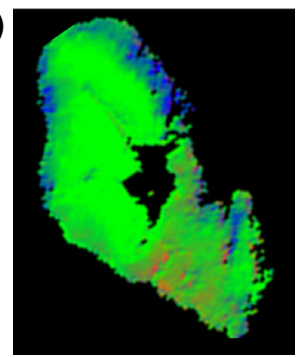

$\mathrm{CdCO}_{3}$

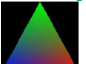

Remainder CdS

(e)

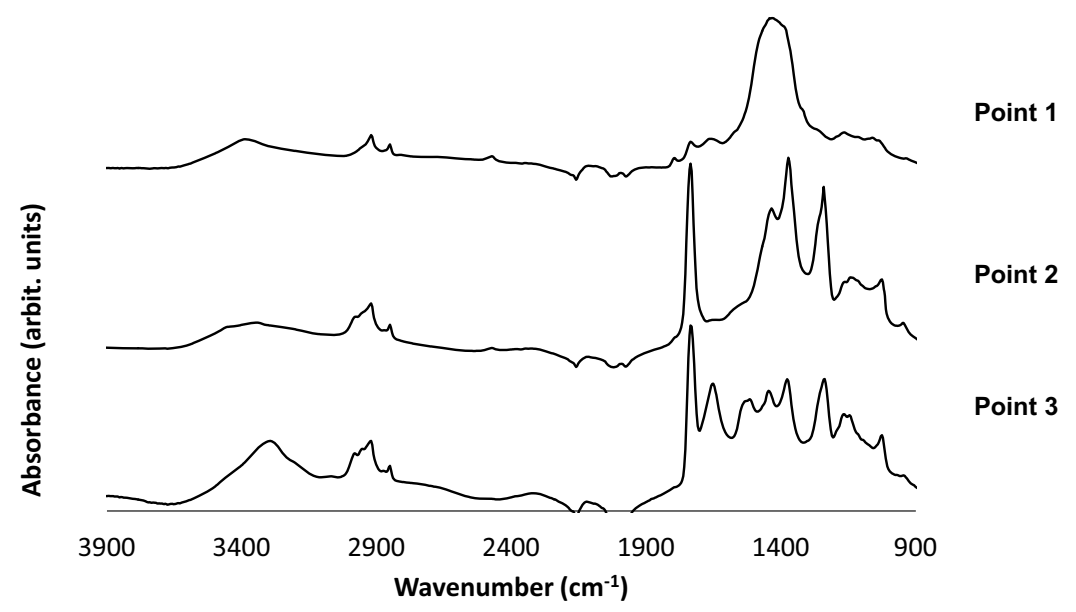

Fig. 3 Combination of SR $\mu$ FTIR, $\mu$ XRF, and FF-XANES for the study of a fragment from The Joy of Life (S5). Schematic views of results obtained with b $\mu$ FTIR and $\mu$ XRF; g FF- XANES at the $\mathrm{Cd} \mathrm{L}_{\mathrm{III}}$-edge and $\mu \mathrm{XRF}$; $\mathbf{c}-\mathbf{e}$ results from the compressed fragment displayed in a Visible light microscope image; c $\mu \mathrm{XRF}$ elemental maps of $\mathrm{Cd}, \mathrm{S}$, and $\mathrm{Cl}$ (step size: $1 \times 1 \mu^{2}$ ). d $\mu$ FTIR maps of esters $\left(1710-1750 \mathrm{~cm}^{-1}\right)$, amides $\left(1616-1700 \mathrm{~cm}^{-1}\right)$, hydroxyls (3320-3450 $\left.\mathrm{cm}^{-1}\right)$, sulphates $\left(1022-1206 \mathrm{~cm}^{-1}\right)$, oxalates

upper left corner) and are thought to be the residual starting reagent from the wet process synthesis of the $\mathrm{CdS}$ used for this painting [11]. This conclusion is also supported by our present findings where cadmium chlorides are found in the internal yellow region, rather than accumulated in the alteration white crust (which would be the case if introduced as a contaminant from the environment).
(1306-1327 $\left.\mathrm{cm}^{-1}\right)$, and carbonates $\left(1342-1535 \mathrm{~cm}^{-1}\right)$ (step size: $6 \times 6 \mu \mathrm{m}^{2}$ ); e IR spectra of carbonates (point 1), poly (vinyl acetate) polymer (point 2), and zein (point 3)-rich area; f-i results from the $10-\mu \mathrm{m}$-thick section displayed in $\mathbf{f}$ Visible light microscope image. h $\mu$ XRF elemental maps of $\mathrm{Cd}, \mathrm{S}$ and $\mathrm{Cl}$ (step size: $1 \times 1 \mu \mathrm{m}^{2}$ ); i Speciation maps (FF-XANES) of $\mathrm{CdCO}_{3}, \mathrm{CdS}$ as well as the sum of the remainder Cd components used in LSLC fitting $\left(\mathrm{CdCl}_{2} \cdot \mathrm{nH}_{2} \mathrm{O}\right.$ and $\left.\mathrm{CdSO}_{4} \cdot \mathrm{nH}_{2} \mathrm{O}\right)\left(\right.$ pixel size: $0.3 \times 0.3 \mu \mathrm{m}^{2}$ )

Concerning the white altered layer, chemical mapping highlights a complex stratigraphy mainly composed of $\mathrm{CdCO}_{3}$ ( $\mu$ FTIR, Fig. 3d, e point1, and XANES at $\mathrm{Cd} \mathrm{L}_{\mathrm{III}^{-}}$ edge, Fig. $3 \mathrm{i}$ and Online Resource(2)). In the upper part of the white layer, both sulphates and oxalates are also identified ( $\mu$ FTIR, Fig. 3d, XANES at the $\mathrm{Cd} \mathrm{L}_{\mathrm{III}}$-edge, Fig. $3 i$ and Online Resource (2), and chemical maps at the 

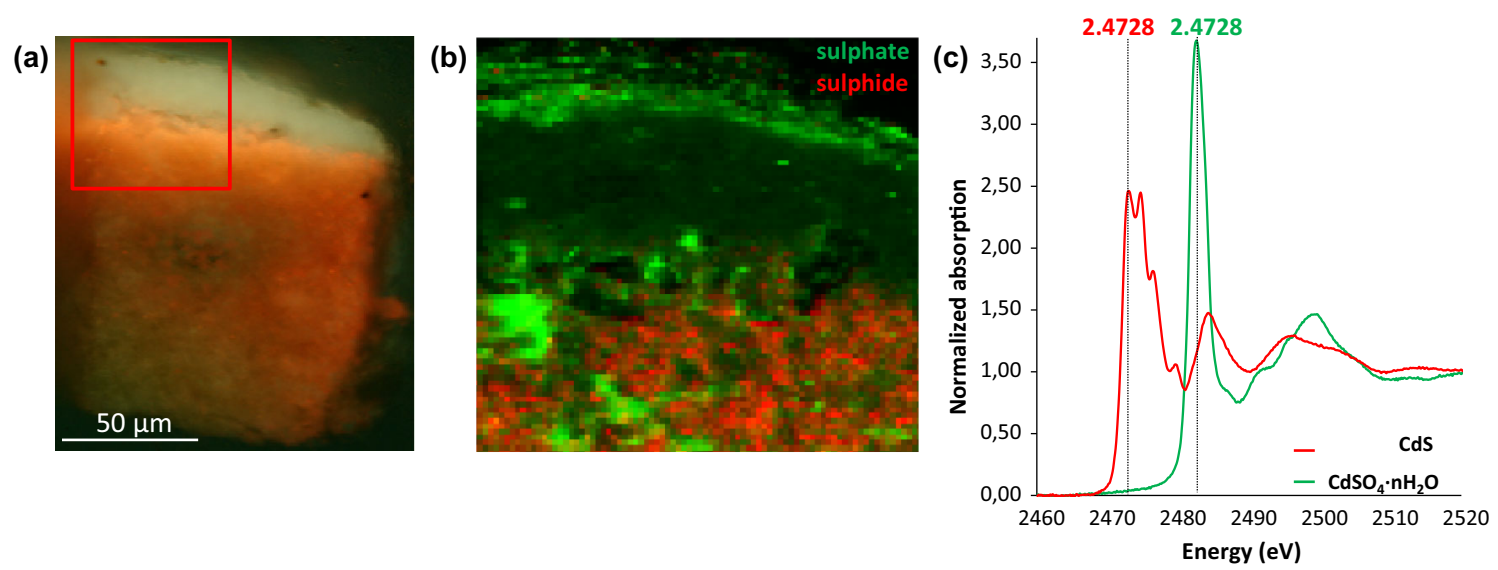

Fig. $4 \mu \mathrm{XRF}$ maps of sulphur, in The Joy of Life (BF 719), sample S5 from below the central reclining figures. a UV picture of S5 cross section; b XRF maps were acquired at 2.4728, 2.4825, and

S K-edge, Fig. 4). Since the oxalates, carbonates, and sulphates are all colourless, it explains the chemical cause of the fading observed in the altered region.

The cadmium carbonates are enriched in the white superficial layer (Fig. 3d, i) where CdS is completely absent (Figs. 3i, Fig. 4). They can also be observed in smaller quantities in the yellow paint layer. This distribution confirms similar results found in the altered yellow fruits from the same work, suggesting that in the off-white alteration layer, the cadmium carbonate is a photo-degradation product, even though it has been suggested as a residue of the CdS synthesis in other systems [10, 11].

The presence of $\mathrm{CdC}_{2} \mathrm{O}_{4}$ is limited to the uppermost alteration layer (Fig. 3d, i and Online Resource (2)). Also observed in the darkened foliage in the upper left corner of The Joy of Life [11] and a painting by Van Gogh [8], this product is identified as a degradation product, derived from either varnish residues on the painting (residues of a partially removed natural resin varnish have been observed in several paint cross sectional samples removed from the piece) or from the oil binder. Such degradation could be the result of a cleaning treatment, natural ageing, or the breakdown of the binder during the photo-degradation process.

As seen in earlier examples of altered cadmium sulphide-containing paints, cadmium sulphates are distributed throughout the paint layer [11] (Fig. 3d, i), see, for example, the data from sample S115. The distribution of sulphide and sulphate species (Fig. 4), obtained in $\mu \mathrm{XRF}$ mode on cross sections [7]), shows that sulphates (presumably cadmium sulphate) are dispersed in the original paint layer, but are also enriched on the surface of the offwhite alteration crust. Cadmium sulphide is virtually absent in this upper layer, consistent with the absence of a yellow colour in this region, whereas it is intact beneath the
$2.5189 \mathrm{keV}$ highlighting the relative distribution of sulphides ( $\mathrm{red}$ ) and sulphates (green), respectively; c Reference XANES spectra at the S K-edge of CdS and $\mathrm{CdSO}_{4} \cdot \mathrm{nH}_{2} \mathrm{O}$.

alteration crust. These data are again consistent with cadmium sulphates being photo-degradation products rather than residues of the CdS synthesis in The Joy of Life paints.

$\mu$ FTIR also revealed the presence of an organic compound made up of a poly(vinyl acetate) polymer (Fig. 3e, point 2) characterized by a strong peak in the $\mathrm{C}-\mathrm{O}$ stretching absorption region (1300-900 $\mathrm{cm}^{-1}$ ). This product is likely a restoration/consolidation material used to reduce flaking. Flaking and spalling were particularly problematic in this region of the painting, and several campaigns of consolidation have been carried out, in particular to allow the work to travel in 1992. In a Cd-free area of about $50 \mu \mathrm{m}$ (Fig. 3c), the $\mu$ FTIR spectra exhibit a peculiar feature, characteristic of amides. Comparison with databases suggests the presence of zein, characterized by a band at $3286 \mathrm{~cm}^{-1}$ from amide A (Fig. 3e point3). Zein is the major storage protein of maize and was proposed as a possible base material for polymer applications in the early twentieth century [26]; here, it is again interpreted as a restoration treatment-the painting is known to have been stabilized with a glue lining in the early twentieth century, prior to the polymer-based consolidation treatments.

\subsubsection{S111 sample: darkened yellow foliage}

Another discoloured area of The Joy of Life (1905-1906), from the darkened upper left corner, was also sampled: sample S111. Since this fragment was very small, it was impossible to employ more than one sample preparation strategy. Priority was given to XANES analysis at the $\mathrm{Cd}$ and $\mathrm{S}$ edges, and thus, a $10-\mu \mathrm{m}$-thick thin section was prepared. Contrary to the previous fragment, no white alteration zone was observed (Fig. 5a). The white thick layer visible in the optical image relates to the lead white-rich ground layer identified by $\mu \mathrm{XRF}$ analyses as a mixture of 
Ba- and S-containing coarse grains (previously identified as barium sulphates, Fig. 5b), dispersed in a $\mathrm{Pb}$ whitebased matrix (lead white, Fig. 5b). The degradation seems to be limited to a few micrometres on the uppermost part of the $\mathrm{Cd}$ yellow paint and is related to the browning of the original yellow pigment.

The section has been analysed using FF-XANES at the $\mathrm{S}, \mathrm{Cl}$ K-edge, and $\mathrm{Cd} \mathrm{L}_{\mathrm{III}}$-edges. Supplementary $\mu \mathrm{XRF}$ maps were also acquired at a primary energy of $3.7 \mathrm{keV}$. After exposing the sample to these multiple XANES and XRF acquisitions, the embedding resin started to lose its mechanical strength, thus preventing further investigation using other techniques such as FTIR or XRD. At the S K-edge, over-absorption issues prevented reliable LSLC fitting, limiting data analysis to the localization of both sulphide and sulphate species based on ROI calculations (as described in Online Resource (4); results not shown). At the $\mathrm{Cl} \mathrm{K}$-edge, the main information obtained was the identification of $\mathrm{CdCl}_{2} \cdot \mathrm{nH}_{2} \mathrm{O}$ as the single chlorine-containing compound present. Both results were used to con-

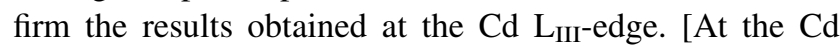
$\mathrm{L}_{\mathrm{III}}$-edge, some pixels suffered from over-absorption and were set to zero (and therefore not taken into account during data fitting).]

LSLC, using similar references to those used for the S5 sample, presented a large difference between experimental data and fit results, suggesting the presence of species not covered by the reference data set. In order to identify the relevant cadmium spectral basis set, principal component analysis was used. PCA followed by k-means clustering using the PC basis identified four main clusters (Fig. 5c): clusters $1,3,5$, and 6 (cluster 2 and 4 are related to low absorbing area with noisy pixels and were not retained for further analysis). From each cluster, the average XANES of the cluster was extracted and fitted with the complete list of references presented above. Mixtures of $\mathrm{CdS}, \mathrm{CdSO}_{4}$, (a)
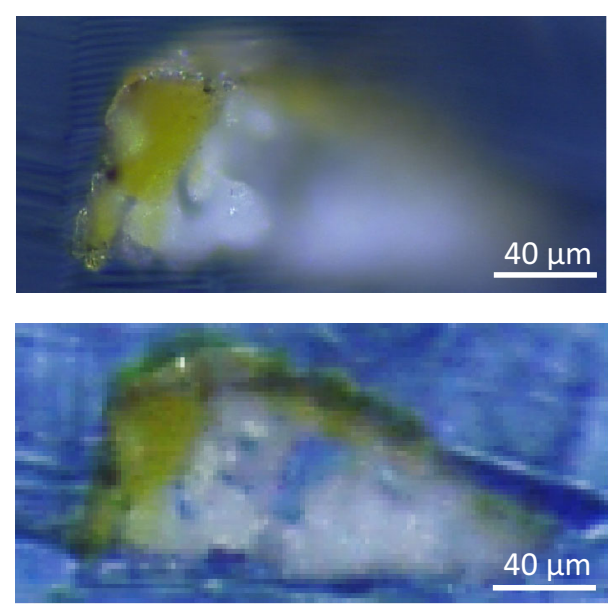

(c)

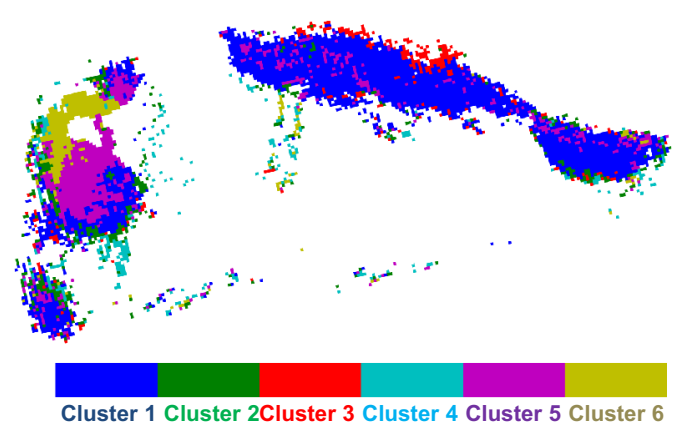

Fig. 5 a Visible light microscope images of S111 $10 \mu \mathrm{m}$-thick thin section; $\mathbf{b} \mu \mathrm{XRF}$ elemental maps of $\mathrm{Cl}, \mathrm{K}, \mathrm{S}, \mathrm{Cd}$, and $\mathrm{Pb}$ acquired at $3.7 \mathrm{keV}$ (step size: $0.7 \times 0.7 \mu \mathrm{m}^{2}$ ); $\mathbf{c}$ Results of $\mathrm{k}$-means clustering

(b)
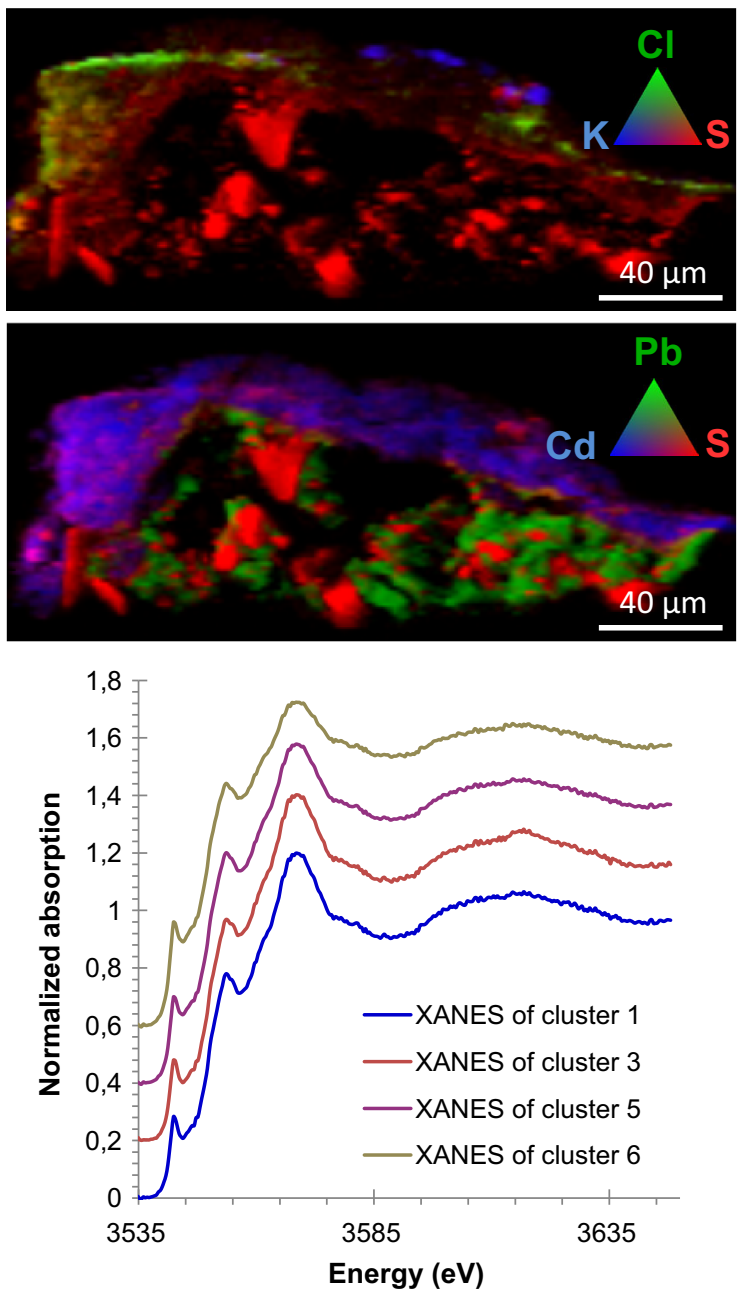

combined with PCA analyses of FF-XANES acquisition at $\mathrm{Cd} \mathrm{L}_{\mathrm{III}}{ }^{-}$ edge (step size: $0.7 \times 0.7 \mu \mathrm{m}^{2}$ ) 
$\mathrm{CdSO}_{4} \cdot \mathrm{nH}_{2} \mathrm{O}, \mathrm{CdCO}_{3}$, and $\mathrm{CdCl}_{2} \cdot \mathrm{nH}_{2} \mathrm{O}$ were able to fit the $\mathrm{XANES}$ for the four clusters adequately. The full spectral stack was then refitted using the spectra for the clusters identified above, leading to a significantly improved fit.

Cluster 1 is representative of most of the sample. Its content of $\mathrm{CdCO}_{3}$ is higher than that of any other cluster; it also contains traces of $\mathrm{CdS}$ and $\mathrm{CdCl}_{2} \cdot \mathrm{nH}_{2} \mathrm{O}$. On the surface of this cluster is cluster 3 , which displays a similar composition but with added $\mathrm{CdSO}_{4} \cdot \mathrm{nH}_{2} \mathrm{O}$, again in significantly lower concentration than $\mathrm{CdCO}_{3}$. Below the surface of the left corner (yellow), cluster 5 reveals an area where the $\mathrm{CdS}$ content increases but still contains a relatively high amount of $\mathrm{CdCO}_{3}$. Consequently, even in the CdS-rich yellow region, the $\mathrm{CdCO}_{3}$ is found in high amounts, suggesting that a large fraction of the $\mathrm{CdCO}_{3}$ present is possibly unreacted starting reagent [11]. However, further investigation is needed because the cadmium yellow hue in this region of the painting was intended to be a dark yellow/orange (based on comparison with a 1905 study of The Joy of Life at The San Francisco Museum of Modern Art and the Statens Museum for Kunst, Copenhagen), and $\mathrm{CdCO}_{3}$ has typically been observed at high concentrations in the paler shades of cadmium yellow. Another explanation for the $\mathrm{CdCO}_{3}$-rich interior of this yellow paint is the relatively thin paint layer being studied here compared to samples S115 [11] or S5, which represent more advanced states of alteration where discrete alteration crusts are visible. The entire yellow paint layer in this case may be in the process of converting into an alteration zone.

On the surface of this area is cluster 6 that is highly concentrated in $\mathrm{Cd}(\mu \mathrm{XRF})$, present mainly as $\mathrm{CdS}$, and $\mathrm{CdCO}_{3}$. The high concentration of $\mathrm{CdS}$ in this region of the sample may be due to the morphology of the brushstroke observed (Fig. 5a). The top of the sample would be more exposed to direct ambient light, whereas the texture/impasto of the paint that causes yellow paint to appear on both the side and top of this sample may have protected the side from direct exposure.

Contrary to S5, this sample is missing the thick white alteration crust, maybe explaining the lack of a distinct layering structure for the alteration products. However, the distribution and amount of sulphates species suggest advanced photo-degradation. The degradation mechanism appears to be a two-step process; in the first step, sulphides are directly photo-oxidized to sulphates, and in the second stage, sulphur-based species, in particular cadmium sulphide, are completely lost, replaced by cadmium carbonate, as seen for cluster 1 . The presence of some $\mathrm{CdSO}_{4}$ in cluster 5 suggests that the degradation process is still not complete.

However, the visible colour of the degraded sample (ochre brown) is not directly linked here to the identification of Cd-based compounds. Consequently, supplementary $\mu$ XRD analyses and organic phase analyses are now mandatory to fully understand the photo-degradation mechanism in this sample.

\subsection{Flower Piece: degradation and synthesis processes study}

\subsubsection{Darkened BF205 sample}

Another micro-sample of cadmium yellow paint from the painting Flower Piece (1906), demonstrating photodegradation, was taken from the dry, cracked, and darkened region below the right side of the painting's pitcher. The sample was too brittle to allow sectioning without adding strengthening material, consequently the surface of the resin block was first covered with a sulphur-free tape insuring the integrity of the $10 \mu \mathrm{m}$ section during slicing with the microtome (Fig. 6a). The optical stratigraphy is very similar to that observed in sample S5, with an offwhite layer at the surface of the painting. A residual ground layer was also identified on the left corner of the section.

Four main experiments were carried out on this section in order to identify the degraded materials present: $\mu \mathrm{XRF}$ sulphur valence maps (step size $2 \times 2 \mu \mathrm{m}^{2}$ ); results are presented in Fig. 6b. $\mu$ XRF at $7.3 \mathrm{keV}$ (step size $2 \times 2 \mu \mathrm{m}^{2}$ ); elemental mapping results are illustrated in Fig. 6c. FF-XANES at $\mathrm{Cd} \mathrm{L}_{\mathrm{III}}$-edge (pixel size $0.7 \times 0.7 \mu \mathrm{m}^{2}$ ); results of LSLC fitting are presented in Fig. 6d. $\mu$ XRD $12.9 \mathrm{keV}$ (ID13, step size $2 \times 2 \mu \mathrm{m}^{2}$ ); phase maps based on the integrated diffraction intensity over regions of interest are shown in Fig. 6e.

Based on these four techniques, the painting's ground layer, paint layer, and alteration layer could be chemically characterized.

$\mu$ XRD (Fig. 6e) combined with $\mu$ XRF (Fig. 6c) allowed for the identification of sphalerite $(\mathrm{ZnS})$, barite $\left(\mathrm{Ba}_{0.99} \mathrm{Sr}_{0.01}\left(\mathrm{SO}_{4}\right)\right)$, anglesite $\left(\mathrm{PbSO}_{4}\right)$, and hydrocerussite $\left(\mathrm{Pb}_{3}\left(\mathrm{CO}_{3}\right)_{2}(\mathrm{OH})_{2}\right)$ in the ground layer area. Two different ground layers were more accurately identified: the first one (innermost) contains mainly hydrocerussite with sphalerite and barite on which a very thin second layer containing hydrocerussite and barite with grains of anglesite is applied. The presence of sphalerite and barite together suggests the use of lithopone, a co-precipitate of $\mathrm{BaSO}_{4}$ and $\mathrm{ZnS}$ introduced in 1874 . The first layer may be a commercial ground, while the second has probably been prepared and applied by Matisse himself. The anglesite was also seen by $\mu$-FTIR in The Joy of Life and may result from the interaction of the unstable CdS with the lead white in the ground.

By combining FF-XANES at ID21 at the $\mathrm{Cd}_{\mathrm{III}}$-edge with $\mu \mathrm{XRD}$ and $\mu \mathrm{XRF}$ at sulphide and sulphate absorptionspecific energies, the composition of the painting layer is 

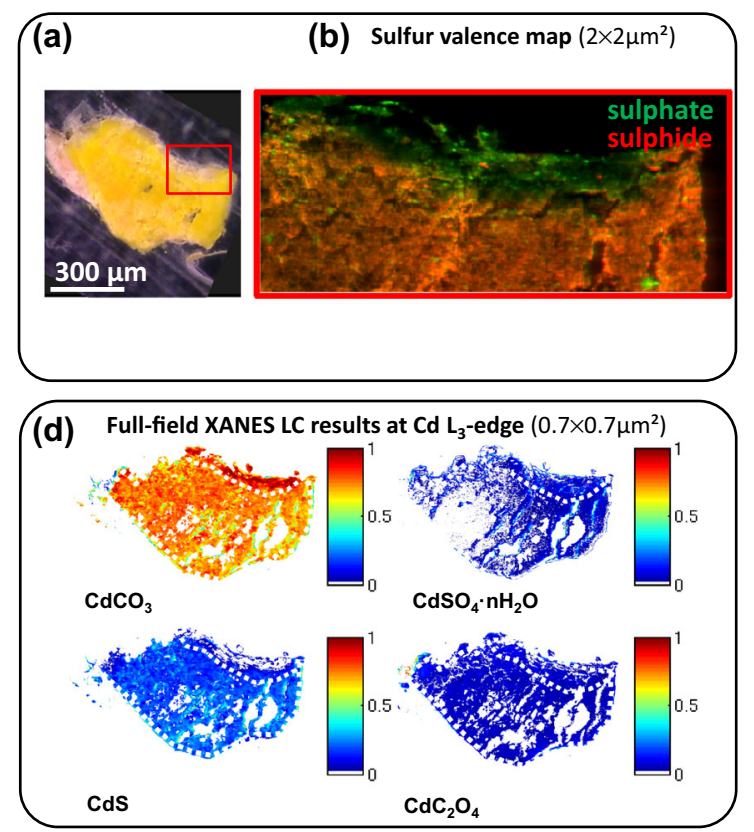

Fig. 6 a Optical image of BF205 darkened sample prepared as $10-\mu \mathrm{m}$-thick thin section (bottom); b Sulphide and sulphate distribution from sulphur valence maps in $\mu \mathrm{XRF}$ (step size: $1 \times 1.2 \mu \mathrm{m}^{2}$ ); c Elemental mapping results from fit of XRF map (step size: $\left.2 \times 2 \mu \mathrm{m}^{2}\right)$; d LSLC fitting results of full-field stack acquired at Cd $\mathrm{L}_{\mathrm{III}}$-edge on the thin section using $\mathrm{CdS}, \mathrm{CdCO}_{3}, \mathrm{CdCl}_{2} \cdot \mathrm{nH}_{2}$, and

defined mainly as a mixture of $\mathrm{CdS}, \mathrm{CdCO}_{3}$, and $\mathrm{CdSO}_{4} \cdot \mathrm{nH}_{2} \mathrm{O}$.

The white degraded area is mainly composed of $\mathrm{CdCO}_{3}$ with a small amount of $\mathrm{CdC}_{2} \mathrm{O}_{4}$ and $\mathrm{CdSO}_{4} \cdot \mathrm{nH}_{2} \mathrm{O}$, identified by FF-XANES and $\mu$ XRD, similar to what was observed for samples $\mathrm{S} 5$ and $\mathrm{S} 115$ [11]. A small increase in the $\mathrm{CdC}_{2} \mathrm{O}_{4}$ and $\mathrm{CdSO}_{4} \cdot \mathrm{nH}_{2} \mathrm{O}$ content is observed at the surface of this area in FF-XANES data; however, no clear stratigraphy inside the degraded area was observed from the $\mu$ XRD results.

The high concentration of $\mathrm{CdCO}_{3}$ in the off-white alteration crust of the paint layer may suggest that this compound as well as $\mathrm{CdSO}_{4} \cdot \mathrm{nH}_{2} \mathrm{O}$ and $\mathrm{CdC}_{2} \mathrm{O}_{4}$ are the products of degradation processes. However, the presence of $\mathrm{CdCO}_{3}$ in a high amount in the paint layer as well suggests that at least some of it may have been initially present as a filler or residual starting reagent for this work. Though the former possibility is less likely since $\mathrm{CdCO}_{3}$, used as cadmium white, would have been an expensive filler [10].

\subsubsection{Undarkened BF205 sample}

Cadmium carbonate $\left(\mathrm{CdCO}_{3}\right)$, as illustrated above, has been identified in the altered cadmium yellow $(\mathrm{CdS})$ paints found in Impressionist, early modernist, and post-Impressionist works. As $\mathrm{CdCO}_{3}$ is highly insoluble $\left(\mathrm{K}_{\mathrm{sp}}\right.$ of
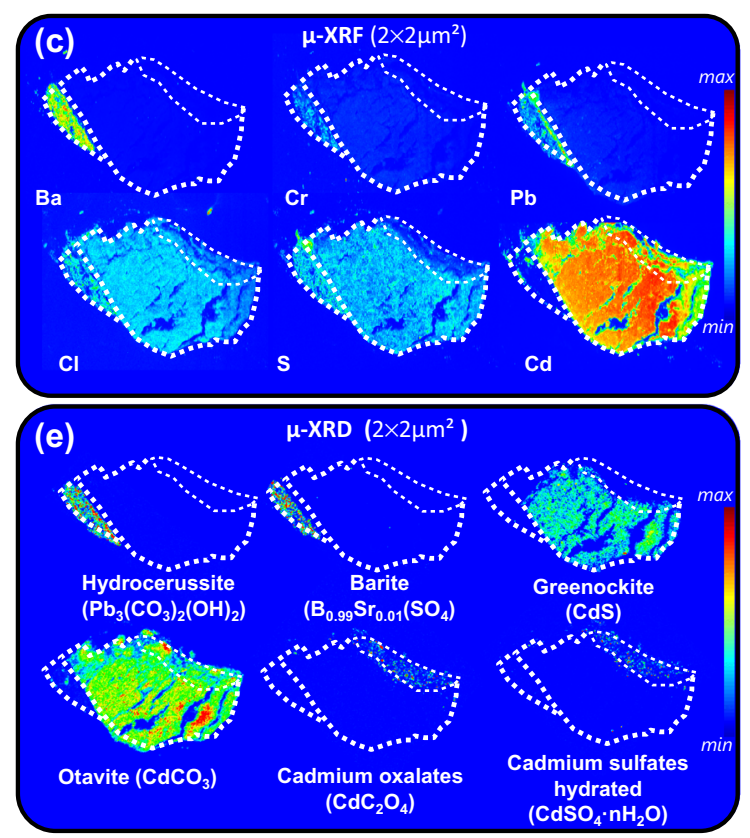

$\mathrm{CdSO}_{4} \cdot \mathrm{nH}_{2} \mathrm{O}$ (pixel size: $0.7 \times 0.7 \mu \mathrm{m}^{2}$ ); e $\mu$ XRD maps of sphalerite $(\mathrm{ZnS})$, barite $\left(\mathrm{Ba}_{0.99} \mathrm{Sr}_{0.01}\left(\mathrm{SO}_{4}\right)\right)$, anglesite $\left(\mathrm{PbSO}_{4}\right)$, hydrocerussite $\left(\mathrm{Pb}_{3}\left(\mathrm{CO}_{3}\right)_{2}(\mathrm{OH})_{2}\right)$, CdS, cadmium oxalate $\left(\mathrm{CdC}_{2} \mathrm{O}_{4}\right)$, cadmium sulphate hydrated $\left(\mathrm{CdSO}_{4} \cdot \mathrm{nH}_{2} \mathrm{O}\right)$, and otavite $\left(\mathrm{CdCO}_{3}\right)$ (step size: $2 \times 2 \mu \mathrm{m}^{2}$ )

$1.0 \times 10^{-12}$ ), when it is formed solely as a result of photoalteration, it is mostly confined to the location where it is formed, i.e. at the surface of the paint layer. However, when an unclear stratigraphy is present and $\mathrm{CdCO}_{3}$ is distributed throughout the paint layer, conclusions about its origin in the paint layer are equally unclear. In cadmium yellow paint in works such as Edvard Munch's The Scream (c. 1910, The Munch Museum, Oslo), the hypothesis has recently been proposed that $\mathrm{CdCO}_{3}$ was used in the indirect wet process synthesis of CdS (for example, through reaction of $\mathrm{CdCO}_{3}$ with $\mathrm{Na}_{2} \mathrm{~S}$ ) $[10,11]$.

To address the question of the origin of $\mathrm{CdCO}_{3}$, a flake of (to the naked eye) undegraded pale cadmium yellow paint was removed from Henri Matisse's Flower Piece so that the distribution of $\mathrm{CdCO}_{3}$ could be studied, both as a function of depth in the paint layer and in individual pigment particles. The visible fluorescence of the ultravioletilluminated paint cross section removed from Flower Piece (Fig. 7a) shows that in the top half of this sample, the cadmium yellow is dispersed in a zinc white base and individual cadmium sulphide particles are visible thanks to their orange fluorescence in the ultraviolet. A section of $15 \mu \mathrm{m}$ thickness was prepared from a visually non-degraded paint fragment from the lemon yellow area (Fig. 7b).

Three main measurement types were carried out on this section to identify possible residual starting reagents: 

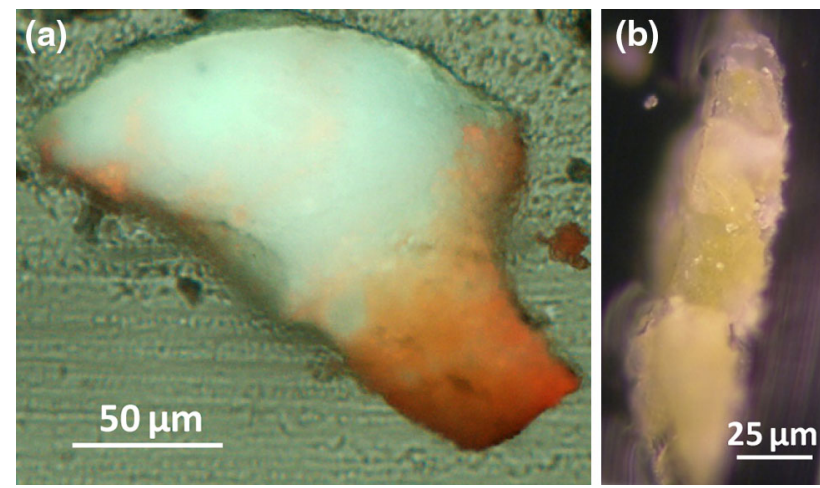

Fig. 7 a Lemon cadmium paint cross section from Flower Piece (BF 205) showing cadmium yellow particles dispersed in a zinc white matrix (405 nm illumination), b Optical image of the lemon-hued cadmium paint prepared as thin section, $15 \mu \mathrm{m}$ thick

$\mu \mathrm{XRD}$ at $21 \mathrm{keV}$ (P06, step size $2 \times 2 \mu \mathrm{m}^{2}$ ), results presented in Fig. 8b; FF-XANES at the S K-edge (ID21, pixel size $0.7 \times 0.7 \mu \mathrm{m}^{2}$ ), analysed as ROI integration (Online Resource (4)); and FF-XANES at the Cd $\mathrm{L}_{\mathrm{III}}$-edge (ID21, pixel size $0.7 \times 0.7 \mu \mathrm{m}^{2}$ ), analysed by LSLC fitting and presented in Fig. 8c.
The Cd concentration map derived from FF-XANES at the $\mathrm{Cd} \mathrm{L}_{\mathrm{III}}$-edge reveals that cadmium-containing particles show up as "hot spots" evenly dispersed throughout the zinc white base. The presence of $\mathrm{CdCO}_{3}$ grains is established by FF-XANES at the $\mathrm{Cd}_{\mathrm{III}^{-}}$-edge and by $\mu \mathrm{XRD}$ (Fig. 8b, c). The XRD measurements show CdS as a diffuse halo in the vicinity of the larger $\mathrm{CdCO}_{3}$ grains. The $\mathrm{Cd}$ $\mathrm{L}_{\mathrm{III}}$ FF-XANES results suggest that cadmium sulphide and sulphate form rings/shells surrounding the $\mathrm{CdCO}_{3}$ grains. This observation is supported by sulphide and sulphate maps acquired at S K-edge in FF-XANES mode (Online Resource (4)). However, the larger beam size and the relative insensitivity of XRD to poorly crystalline material did not allow confirming the sulphate/sulphide/carbonate morphology suggested by the FF-XANES measurements by diffraction imaging.

Even though XRD cannot confirm the core/shell morphology of the $\mathrm{CdCO}_{3}$ particles surrounded by $\mathrm{CdS}$ or $\mathrm{CdSO}_{4}$, it clearly shows that in this sample, $\mathrm{CdCO}_{3}$ is colocalized with $\mathrm{CdS}$ instead of forming a surface degradation layer.

The co-localized core and shell morphology suggests that a large fraction of $\mathrm{CdCO}_{3}$ in this sample is residual

(a)
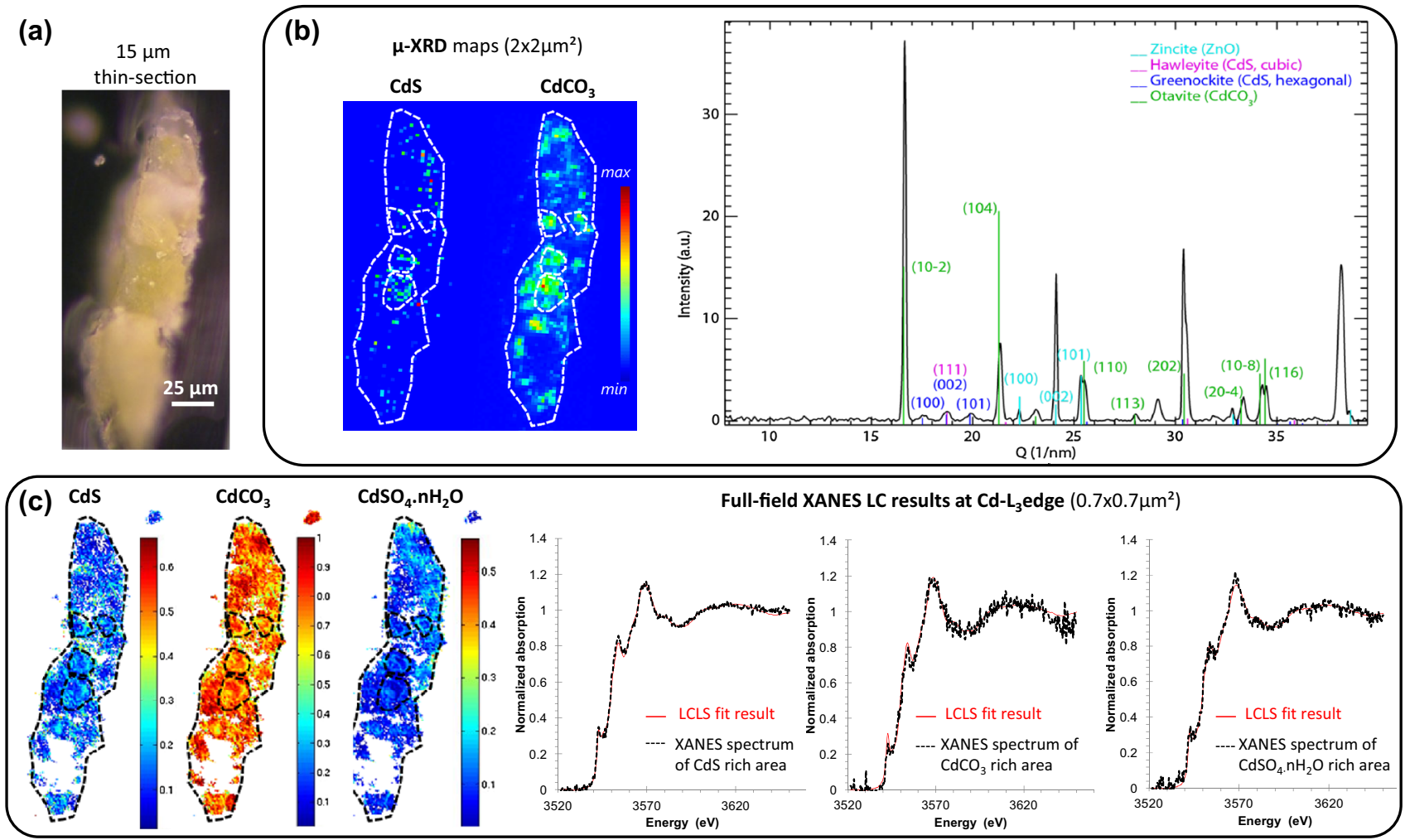

Fig. $8 \mu X R D$ and FF-XANES acquisition on the thin section presented in $\mathbf{a} ; \mathbf{b} \mu \mathrm{XRD}$ maps of $\mathrm{CdS}$ and otavite $\left(\mathrm{CdCO}_{3}\right)$ (step size: $2 \times 2 \mu \mathrm{m}^{2}$ ), and $\mu$-XRD Q-patterns acquired on CdS-rich grain; c CdS, $\mathrm{CdCO}_{3}$, and $\mathrm{CdSO}_{4} \cdot \mathrm{nH}_{2} \mathrm{O}$ maps obtained by FF-XANES at the
Cd L-III edge, and examples of LSLC fitting results of single pixel XANES spectra acquired in $\mathrm{CdCO}_{3}, \mathrm{CdS}$, and $\mathrm{CdSO}_{4} \cdot \mathrm{nH}_{2} \mathrm{O}$-rich areas 
starting reagent. Conversion to $\mathrm{CdS}$ was incomplete; the large and poorly soluble $\mathrm{CdCO}_{3}$ particles were trapped during the precipitation reaction of $\mathrm{CdS}$, coated by a thin layer of nanocrystalline CdS. This example might be the first evidence confirming the precipitation process hypothesized by Plahter and Topalova-Casadiego [10] for the role of cadmium carbonate identified in the yellow paints of the Munch Museum version of The Scream. To fully confirm their theory, a similar investigation should be performed on a cross section from a relatively non-degraded region to ascertain whether or not this same pattern of precipitation ( $\mathrm{CdS}$ coating $\mathrm{CdCO}_{3}$ starting material) is also present in yellow paints of the Munch Museum version of The Scream. Further analyses of this cross section, as well as analyses of replicate cadmium yellow pigments synthesized from $\mathrm{CdCO}_{3}$ following early twentieth century recipes, should also be considered at better resolutions.

\section{Conclusion}

The composition of sub-millimetre fragments of cadmium yellow paints from The Joy of Life and Flower Piece as a function of depth using SR- $\mu$ FTIR, $\mu \mathrm{XRF}, \mu \mathrm{XRD}$, and FFXANES imaging confirmed that $\mathrm{CdCO}_{3}, \mathrm{CdC}_{2} \mathrm{O}_{4}$, and $\mathrm{CdSO}_{4} \cdot \mathrm{nH}_{2} \mathrm{O}$ are degradation products rather than paint fillers, and, in the case of The Joy of Life, that these compounds are not residual synthesis reagents either.

These colourless compounds are responsible for the observed fading of the cadmium yellow paint in The Joy of Life. Despite the high solubility that causes cadmium sulphate to migrate through the paint layers in many of the samples studied, cadmium sulphate is also identified as a photo-degradation product. In the case of sample S5 (from The Joy of Life) and sample BF205-darkened (from Flower Piece), an oxidation of the original CdS pigment, probably induced by UV-visible irradiation and uncontrolled relative humidity levels is the initiation point and basis of the observed fading and discoloration. Based on previous work $[8,11]$, the oxidation of $\mathrm{CdS}$ to $\mathrm{CdSO}_{4} \cdot \mathrm{nH}_{2} \mathrm{O}$ at or just below the paint surface explains the formation of the $\mathrm{CdSO}_{4} \cdot \mathrm{nH}_{2} \mathrm{O}$ compound which, as it is highly water soluble, may then diffuse through the paint layer. The surface enrichment of $\mathrm{CdSO}_{4} \cdot \mathrm{nH}_{2} \mathrm{O}$ in the case of $\mathrm{S} 5$ suggests that while $\mathrm{CdSO}_{4} \cdot \mathrm{nH}_{2} \mathrm{O}$ has the potential solubility to migrate through the paint layer, surface accumulation resulting from photo-degradation can also be observed. As suggested previously [11], this compound can initiate the subsequent stages of degradation by reacting with $\mathrm{CO}_{2}$ to form $\mathrm{CdCO}_{3}$. Acid hydrolysis of the organic binder or the varnish which leads to spalling and cracking of the paint layer allows for further photo-oxidation of the newly exposed $\mathrm{CdS}$ in the micro-cracks. The very high insolubility $\left(\mathrm{K}_{\mathrm{sp}}\right.$ of
$1.0 \times 10^{-12}$ ) of $\mathrm{CdCO}_{3}$ explains its presence as the dominant end product of a series of degradation reactions. A tertiary degradation process involving the further breakdown of cadmium oxalate into cadmium carbonate cannot be excluded. The presence and the location of $\mathrm{CdC}_{2} \mathrm{O}_{4}$ are for the moment not fully understood, although TOF-SIMS data from this same painting (see this volume) show that long-chain fatty acids are depleted in the regions of CdS alteration, suggesting that the acid hydrolysis of the binding medium is a possible mechanism for the formation of oxalate anions. Alternatively, the presence of varnish, as observed in the case of the S5 sample, may have partially dissolved $\mathrm{CdSO}_{4}$ and freed $\mathrm{Cd}^{2+}$ ions, which in turn may then have precipitated out with $\mathrm{C}_{2} \mathrm{O}_{4}^{2-}$ instead of $\mathrm{SO}_{4}{ }^{2-}$, explaining the formation of a cadmium oxalate film [8].

The pale brownish appearance of the S111 sample appears to be organic in nature as no evidence for the formation of a dark brown inorganic photo-degradation product was established. Soil and other fine particulate may lodge in the interstices of the crumbling paint surface, formed or enhanced during photo-oxidation, giving rise to the darkening observed [11]. Acid hydrolysis of the drying oil paint binder may also result in the formation of chromophores contributing to the darkened appearance. In either case, further analyses of organic degradation products and trace analyses of other particles embedded in the paint are required to fully understand the observed darkening.

Both the intact lemon cadmium paint and photo-oxidized cadmium yellow paint from Flower Piece were examined by UV and VIS photo-microscopy, XRD, and FFXANES. Investigation of undarkened lemon cadmium paint from Flower Piece reveals that a large amount of cadmium carbonate is present; however, it is not accumulated at the paint surface but co-located with individual $\mathrm{CdS}$ yellow pigment particles suspended in a zinc white base. Co-location of $\mathrm{CdS}$ and $\mathrm{CdCO}_{3}$, possibly in a core/ shell morphology suggests that the CdS pigment used by Henri Matisse to paint this work may have contained a large fraction of unreacted starting reagents, leftovers of an incomplete synthesis. This finding provides the first physical evidence supporting the theory of Plahter et al. that cadmium carbonate-rich cadmium yellow paints in the first decade of the twentieth century were likely prepared by the indirect wet process method, and are not invariably indicative of photo-alteration. Consequently, in the case of photo-oxidized paint, the high ratio of $\mathrm{CdCO}_{3}$ compounds present in yellow paint may be related to this starting reagent, whereas the white crust may combine both $\mathrm{CdCO}_{3}$ as a starting reagent and $\mathrm{CdCO}_{3}$ as second degradation product of photo-alteration, as it is found in the presence of $\mathrm{CdSO}_{4} \cdot \mathrm{nH}_{2} \mathrm{O}$ and $\mathrm{CdC}_{2} \mathrm{O}_{4}$.

In final conclusion, analytical methods with a high sensitivity for chemical speciation and ability to map the 
distribution of various compounds at sub-micron resolution are essential for deciphering the synthesis and degradation pathways of pigments in hierarchically complex objects such as paintings. The access to both molecular and structural mapping capabilities by combining FF-XANES, $\mu \mathrm{XRF}, \mu \mathrm{XRD}$, and $\mu \mathrm{FTIR}$ in $2 \mathrm{D}$ is opening new possibilities for the rigorous study of degradation products and mechanisms in paint layers, and more generally for the micro-analysis of artworks for the benefit of these works' long-term preservation.

Acknowledgments This work is supported by the Andrew W. Mellon Foundation, the Barnes Foundation, the Lenfest Foundation, and the National Science Foundation DMR 0415838. The European Synchrotron Radiation Facility are acknowledged for providing beamtime. Barbara Buckley of the Barnes Foundation and Unn Plahter of the University of Oslo are thanked for their many helpful discussions.

\section{References}

1. L. Zanella et al., The darkening of zinc yellow: XANES speciation of chromium in artist's paints after light and chemical exposures. J. Anal. At. Spectrom. 26(5), 1090-1097 (2011)

2. L. Monico et al., Degradation process of lead chromate in paintings by Vincent van Gogh studied by means of synchrotron $\mathrm{X}$-ray spectromicroscopy and related methods. 2. Original paint layer samples. Anal. Chem. 83(4), 1224-1231 (2011)

3. L. Monico et al., Degradation process of lead chromate in paintings by Vincent van Gogh studied by means of synchrotron $\mathrm{X}$-ray spectromicroscopy and related methods. 1. Artificially aged model samples. Anal. Chem. 83(4), 1214-1223 (2011)

4. L. Monico et al., Degradation process of lead chromate in paintings by Vincent van Gogh studied by means of spectromicroscopic methods. 3. Synthesis, characterization, and detection of different crystal forms of the chrome yellow pigment. Anal. Chem. 85(2), 851-859 (2012)

5. L. Monico et al., Degradation process of lead chromate in paintings by Vincent van Gogh studied by means of spectromicroscopic methods. 4. Artificial aging of model samples of coprecipitates of lead chromate and lead sulfate. Anal. Chem. 85(2), 860-867 (2013)

6. L. Monico et al., Degradation process of lead chromate in paintings by Vincent van Gogh studied by means of spectromicroscopic methods. Part 5. Effects of nonoriginal surface coatings into the nature and distribution of chromium and sulfur species in chrome yellow paints. Anal. Chem. 86(21), 10804-10811 (2014)

7. G. Van der Snickt et al., Characterization of a degraded cadmium yellow (CdS) pigment in an oil painting by means of synchrotron radiation based X-ray techniques. Anal. Chem. 81(7), 2600-2610 (2009)

8. G. Van der Snickt et al., Combined use of synchrotron radiation based micro-X-ray fluorescence, micro-X-ray diffraction, micro$\mathrm{x}$-ray absorption near-edge, and micro-fourier transform infrared spectroscopies for revealing an alternative degradation pathway of the pigment cadmium yellow in a painting by Van Gogh. Anal. Chem. 84(23), 10221-10228 (2012)

9. B. Leone et al., The deterioration of cadmium sulphide yellow artists' pigments, in Triennial meeting (14th), The Hague, 12-16 September 2005: preprints, 2005, ed. by James \& James

10. U. Plahter, B. Topalova-Casadiego, The Scream by Edvard Munch: painting techniques and colouring materials, in Studying Old Master Paintings Technology and Practice, ed. by M. Spring. The National Gallery Technical Bulletin 30th Anniversary Conference Postprints (London: Archetype, 2011), pp. 244-252

11. J.L. Mass et al., The photodegradation of cadmium yellow paints in Henri Matisse's Le Bonheur de vivre (1905-1906). Appl. Phys. A 111(1), 59-68 (2013)

12. C.S. Patterson et al., Synchrotron-based imaging FTIR spectroscopy in the evaluation of painting cross-sections. e-Preserv. Sci. 10, 1-9 (2013)

13. J. Mass et al., SR-FTIR imaging of the altered cadmium sulfide yellow paints in Henri Matisse's Le Bonheur de vivre (1905-6) examination of visually distinct degradation regions. Analyst 138(20), 6032-6043 (2013)

14. E. Pouyet et al., Thin-sections of painting fragments: opportunities for combined synchrotron-based micro-spectroscopic techniques. Herit. Sci. 3(1), 3 (2015)

15. E. Pouyet et al., Preparation of thin-sections of painting fragments: classical and innovative strategies. Anal. Chim. Acta $\mathbf{8 2 2}$, 51-59 (2014)

16. M. Salomé et al., The ID21 scanning X-ray microscope at ESRF. J. Phys. Conf. Ser. 425(18), 182004 (2013)

17. M. Cotte et al., Blackening of Pompeian Cinnabar paintings: X-ray microspectroscopy analysis. Anal. Chem. 78(21), 7484-7492 (2006)

18. V.A. Sole et al., A multiplatform code for the analysis of energydispersive X-ray fluorescence spectra. Spectrochim. Acta Part B At. Spectrosc 62(1), 63-68 (2007)

19. B. Fayard et al., The new ID21 XANES full-field end-station at ESRF. J. Phys. Conf. Ser. 425(19), 192001 (2013)

20. Y. Liu et al., TXM-Wizard: a program for advanced data collection and evaluation in full-field transmission X-ray microscopy. J. Synchrotron Radiat. 19(2), 281-287 (2012)

21. U. Boesenberg et al., Mesoscale phase distribution in single particles of LiFePO4 following lithium deintercalation. Chem. Mater. 25(9), 1664-1672 (2013)

22. C.G. Schroer et al., Hard X-ray nanoprobe at beamline P06 at PETRA III. Nucl. Instrum. Methods Phys. Res. Sect. A 616(2-3), 93-97 (2010)

23. W. De Nolf, F. Vanmeert, K. Janssens, XRDUA: crystalline phase distribution maps by two-dimensional scanning and tomographic (micro) X-ray powder diffraction. J. Appl. Crystallogr. 47(3), 1107-1117 (2014)

24. J. Kieffer, D. Karkoulis, PyFAI, a versatile library for azimuthal regrouping, in Journal of physics: conference series (IOP Publishing, 2013)

25. J. Susini et al., Why infrared spectromicroscopy at the ESRF? ESRF Newsl. 41, 24-25 (2005)

26. D. Saviello et al., Synchrotron-based FTIR microspectroscopy for the mapping of photo-oxidation and additives in acrylonitrilebutadiene-styrene model samples and historical objects. Anal. Chim. Acta 843, 59-72 (2014) 